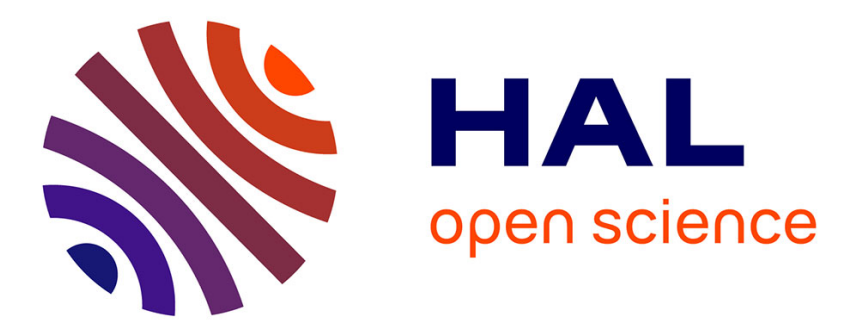

\title{
Parameter analysis of brake squeal using finite element method
}

Guillaume Fritz, Jean-Jacques Sinou, Jean-Marc Duffal, Louis Jézéquel

\section{To cite this version:}

Guillaume Fritz, Jean-Jacques Sinou, Jean-Marc Duffal, Louis Jézéquel. Parameter analysis of brake squeal using finite element method. Revue Européenne de Mécanique Numérique/European Journal of Computational Mechanics, 2007, 16 (1), pp.11-32. 10.3166/remn.16.11-32 . hal-00324087

\section{HAL Id: hal-00324087 \\ https://hal.science/hal-00324087}

Submitted on 1 Oct 2018

HAL is a multi-disciplinary open access archive for the deposit and dissemination of scientific research documents, whether they are published or not. The documents may come from teaching and research institutions in France or abroad, or from public or private research centers.
L'archive ouverte pluridisciplinaire HAL, est destinée au dépôt et à la diffusion de documents scientifiques de niveau recherche, publiés ou non, émanant des établissements d'enseignement et de recherche français ou étrangers, des laboratoires publics ou privés. 


\section{Parameter analysis of brake squeal using finite element method}

Guillaume Fritz* ${ }^{*}$ Jean-Jacques Sinou**
Jean-Marc Duffal* $^{*}$ Louis Jézéquel***

* Renault SAS, Direction de la Recherche, Groupe Acoustique

1 avenue du Golf, F-78288, Guyancourt cedex

** Laboratoire de Tribologie et Dynamique des Systèmes UMR-CNRS 5513

Ecole Centrale de Lyon, 36 avenue Guy de Collongue, F-69134, Ecully cedex

jean-jacques.sinou@ec-lyon.fr

ABSTRACT. Brake Squeal is a friction induced instability phenomenon known to be one of the most annoying noise for drivers. This paper focuses on the mode coupling aspect of brake squeal by means of a multi parametric analysis. The study is based on a Finite Element model of the whole brake corner. A complex eigenvalue analysis is undertaken, with a modal projection technique, to detect the stable and unstable modes. Following this process, the brake stability is assessed as a function of the friction coefficient. The results highlight accurately the modecoupling phenomenon also referred to as coalescence. Then, the emphasis is put on the disc Young modulus variability by launching a numerical design of experiment. Finally, the brake robustness is displayed as functions of the friction coefficient and of the disc Young modulus.

RÉSUMÉ. Le crissement de frein est un phénomène d'instabilité vibratoire induit par le frottement, connu comme l'un des bruits les plus gênants pour le conducteur. Cet article se focalise, grâce à une analyse multiparamètrique, sur la coalescence de modes lors du crissement. L'étude se base sur un modèle éléments finis du système de freinage complet. Une analyse aux valeurs propres complexes est réalisée, avec une technique de projection modale, afin de déterminer quels sont les modes stables et instables. Une étude paramètrique permet de déterminer la stabilité du système en fonction de la valeur du coefficient de frottement. Les résultats décrivent avec précision le phénomène de coalescence. Enfin, un plan d'expérience est lancé afin d'évaluer l'influence du frottement et du module d'Young du disque sur la stabilité du système. KEYWORDS: brake squeal, complex eigenvalue analysis, stability, friction, finite element method. MOTS-CLÉS : crissement de frein, valeurs propres complexes, stabilité, frottement, éléments finis. 


\section{Introduction}

Disc brake noise is a very important and complex problem highlighted by the increase of customer requirements. One of the most common and annoying brake noise is called brake squeal. It belongs to the class of friction induced instability phenomena. This field of mechanical engineering has been studied for years (Mills, 1938; Jarvis et al., 1993; Earles et al., 1976; Earles et al., 1987; Millner, 1978; North, 1972; Ouyang et al., 2001; Ouyang et al., 1999; Ouyang et al., 1998; Kobayashi, 1990; Hulten, 1993; Nakata et al., 2001; Chung et al., 2001; Chung et al., 2003b; Chung et al., 2003a; Moirot et al., 2000a; Blaschke et al., 2000; Baillet et al., 2005; Baillet et al., 2006). Researchers works (Ibrahim, 1994a; Ibrahim, 1994b; Crolla et al., 1991; Oden et al., 1985; Tolstoi, 1967; Rabinowicz, 1965; Sinclair et al., 1955) yield to the identification of four different mechanisms of friction induced instabilities: stick slip (Antoniou et al., 1976; Moirot et al., 2000b; Oueslati et al., 2003; Moirot et al., 2003), negative damping (Gao et al., 1994; Barnejee, 1968), sprag slip (Spurr, 1961) and mode coupling. The trend in brake squeal analysis is to figure out the phenomenon in terms of mode coupling (Jarvis et al., 1993; Earles et al., 1976; Earles et al., 1987; Millner, 1978; North, 1972; Moirot et al., 2000a). The first studies were based on lumped models with few degrees of freedom (Mills, 1938; Jarvis et al., 1993; Earles et al., 1976; Earles et al., 1987; Millner, 1978; North, 1972). More recently, the rise in computer capabilities has made it possible to assess the brake stability on a whole brake finite element model (Kinkaid et al., 2003; Nakata et al., 2001; Chung et al., 2001; Chung et al., 2003b; Chung et al., 2003a; Moirot et al., 2000a; Blaschke et al., 2000; Lorang et al., 2006).

In both cases, the method consists in computing the complex eigenvalues of the system. Hence, its stability is inferred from the eigenvalues real parts signs. This kind of computation helps car and brake manufacturers to improve the NVH (Noise, Vibration and Harshness) performances of brakes. Nevertheless, in spite of the large amount of work done, brake squeal remains a difficult issue to tackle. It might be because the main feature of brake squeal is its sensitive nature. Indeed, experiments show that brake squeal is severely environment dependant. Therefore, the aim is not only to design a quiet brake in nominal conditions but also to ensure it is quiet in the overall operation condition range.

This paper presents a parametric study of brake squeal on an actual front brake. First of all, the finite element model is described. Then, a complex eigenvalue analysis is carried out on this model. The stable and unstable zones with respect to the friction coefficient and the detection of the associated unstable mode are undertaken. Finally, the brake squeal sensitivity with respect to the disc Young modulus has been studied and synthesized. 


\section{Finite element model}

\subsection{Model description}

This study aims at building up a model to assess the squealing behavior of a commercial front disc brake. The scope of the study involves the whole brake corner including disc, anchor bracket, caliper, pads, hub and knuckle. Each part has been meshed and filled in terms of material properties. Parts are linked together by normal contact stiffnesses, as it will be explained in the following section. Once assembled, the whole Nastran model illustrated in Figure 1 has a total of 528000 degrees of free$\operatorname{dom}(D O F)$.

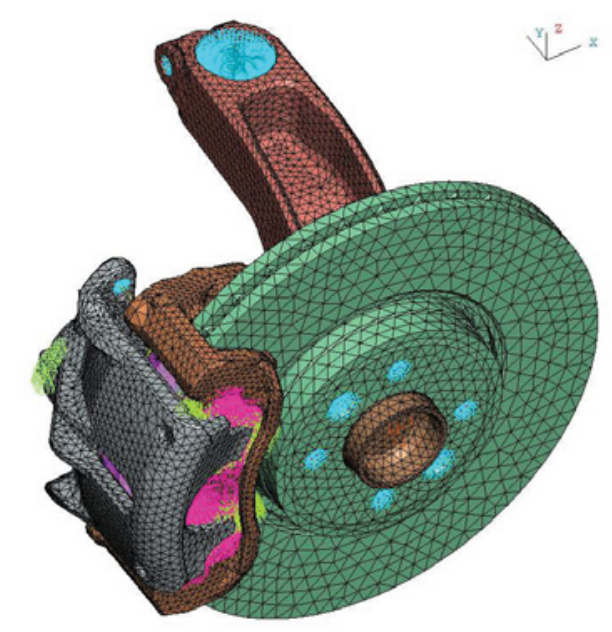

Figure 1. Finite element model

So far, this model is a basic finite element (FE) model which equation of motion is

$$
\mathbf{M u ̈}+\mathbf{K u}=0
$$

where $\mathbf{M}, \mathbf{K}$ and $\mathbf{u}$ are respectively the mass matrix, the stiffness matrix and the displacement vector. Dot denotes derivative with respect to time.

\subsection{Contact definition}

As mentioned in previous works (Matsui et al., 1992; Dihua et al., 1998; Park et al., 2001; Nakata et al., 2001; Chung et al., 2001; Chung et al., 2003b; Chung et al., 2003a), the most convenient way to introduce contact in a brake FE model consists in adding contact stiffnesses between disc and pads. Those springs account for the normal contact force $\mathbf{N}$. In order to consider the tangential force $\mathbf{T}$ induced by friction, the Coulomb law is adopted:

$$
\mathbf{T}=\operatorname{sign}(v) \mu \mathbf{N}
$$


The tangential and normal forces are linked together by the friction coefficient $\mu$ that is assumed to be constant and positive. The sign of $\mathbf{T}$ depends on the sign of the sliding velocity $v$ between disc and pads, which has been defined as positve in the forward direction. This law is sufficient for this study since the relevant mechanism to explain squeal is based on flutter instability (Sinou et al., 2004; Sinou et al., 2003) (i.e. coupling between a stable and an unstable mode) and the non-conservative effect of the Coulomb law.

Once the friction introduced, the equation of motion becomes

$$
\mathbf{M u ̈}+\mathbf{K u}=\mathbf{F}_{\mathbf{f}}
$$

where $\mathbf{F}_{\mathbf{f}}$ denotes the disc-pad friction force. This vector is a sparse vector which non-zero terms correspond to the tangential DOFs of the disc-pads interface. Those non-zero terms are $\pm \mathbf{T}_{\mathbf{i}}$. $i$ is the node index on the disc-pads interface. Thanks to the friction law, those terms can be rewritten as a function of the corresponding normal force $\mathbf{N}_{\mathbf{i}}$. Since $\mathbf{N}_{\mathbf{i}}$ deals with a force between two nodes that are linked by a spring, it depends explicitly on the displacements of those two nodes. Finally, Equation [3] becomes

$$
\mathbf{M} \ddot{\mathbf{u}}+\left(\mathbf{K}+\mathbf{K}_{\mathbf{e q}}\right) \mathbf{u}=0
$$

where $\mathbf{K}_{\mathbf{e q}}$ is the friction induced asymmetrical stiffness matrix. The non-zero terms of this sparse matrix are $\pm \mu k$, where $k$ is the contact stiffness value.

In order to reduce the problem size, Equation [4] is transformed to the modal and frequency domain:

$$
\left(s^{2} \mathbf{I}+\boldsymbol{\Omega}^{\mathbf{2}}+\mu . \boldsymbol{\Lambda}_{\mathbf{f}}\right) \boldsymbol{\Gamma}=0
$$

where $\mathbf{I}$ is the identity matrix. $\boldsymbol{\Omega}^{\mathbf{2}}$ is given by

$$
\boldsymbol{\Omega}^{\mathbf{2}}=\operatorname{diag}\left(\omega_{1}^{2} \cdots \omega_{n}^{2}\right)
$$

with $\omega_{1}, \cdots, \omega_{n}$ the non-friction system frequencies. $\mu . \boldsymbol{\Lambda}_{\mathbf{f}}$ is the projection of $\mathbf{K}_{\mathbf{e q}}$ on the modal basis. $s$ denotes the Laplace parameter and $\boldsymbol{\Gamma}$ the eigenvector coordinates in the non-friction modal basis.

Equation [5] features two main advantages. First, it depends explicitly on the friction coefficient. Second, the three matrices involved can be inferred from a basic normal mode extraction on the non-friction system.

\subsection{Complex eigenvalue analysis}

Since the equivalent stiffness matrix is asymmetrical because of friction, a complex eigenvalue analysis (CEA) is required. Equation [5] can be written as a general eigenvalue problem

$$
\mathbf{A} . \mathbf{X}=\lambda . \mathbf{X}
$$


where $\lambda$ is the eigenvalue and $\mathbf{X}$ the eigenvector. Both are complex valuated. Especially, the eigenvalue may be written

$$
\lambda=a+i b
$$

The real part $a$ and the imaginary part $b$ of the eigenvalue account respectively for the stability and the frequency of the corresponding mode. Indeed the system is stable if its eigenvalue real parts are negative and unstable otherwise.

\section{Sensitivity analysis with respect to the friction coefficient}

As instabilities are induced by friction, the first study to carry out concerns the effect of the friction coefficient on the system eigenvalues. This variability is assessed by solving the eigenvalue problem (Equation [7]). As mentioned previously, the computation of $\mathbf{A}$ requires the knowledge of the friction coefficient value and of the first $m$ normal modes of the non-friction FE model. The modal truncation chosen in this study includes the first 75 modes of the braking system. The problem, which size is $(75 \times 75)$, has been solved in Matlab for each friction coefficient value.

Figure 2 displays all the computed eigenvalues in the complex plane. It highlights the six unstable modes of the system. The values have been normalized with respect to the frequency of the mode that shows the largest real part. This mode which normalized coordinates are $(1,1)$ in the complex plane has been chosen for the following as a reference.

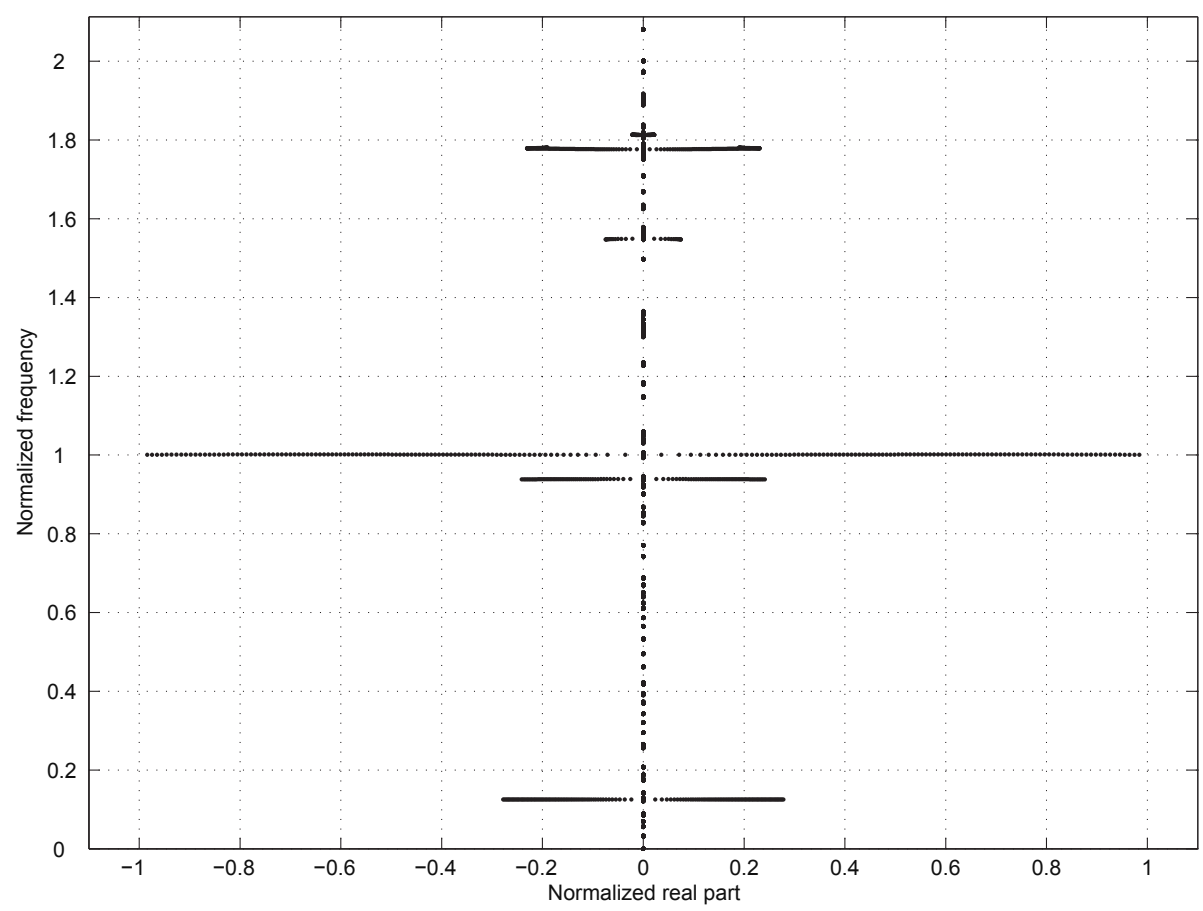

Figure 2. Eigenvalues in the complex plane 
The complex plot graph is an interesting means to sum up the brake stability. However, it does not put the emphasis on the eigenvalues variability with the friction coefficient. Figures 3 and 4 focus on that point by showing in different ways the frequency and the real part of the eigenvalues with respect to friction coefficient.

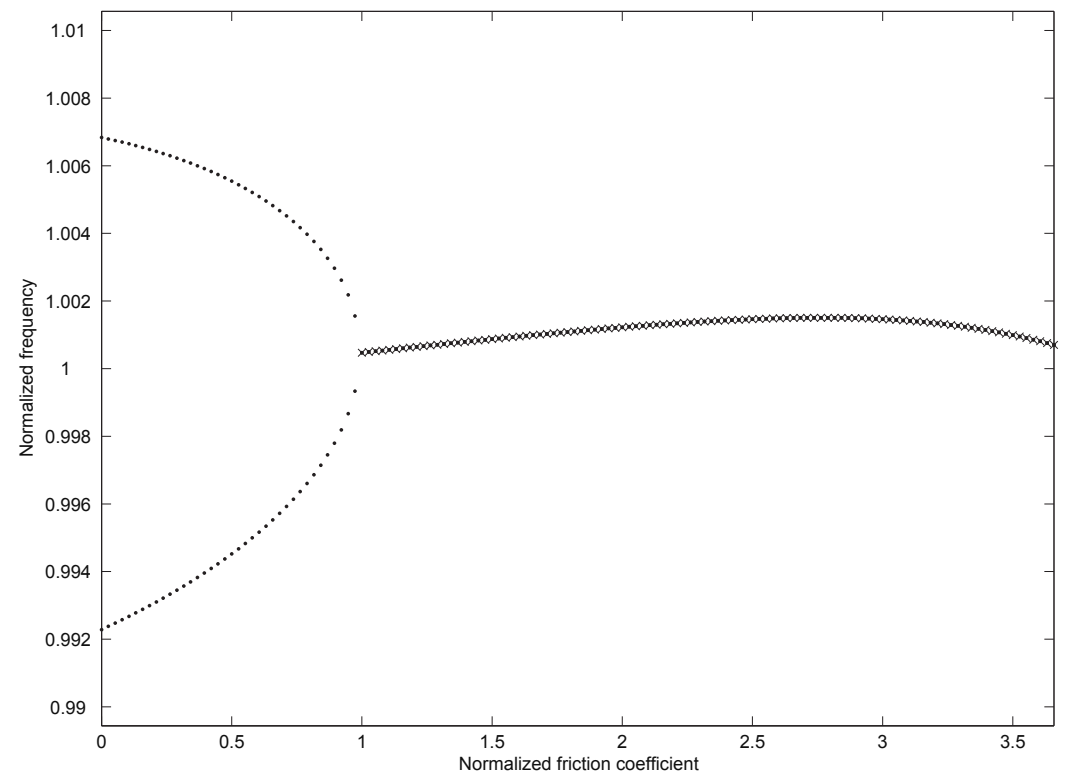

Figure 3. Evolution of the frequencies as a function of the friction coefficient

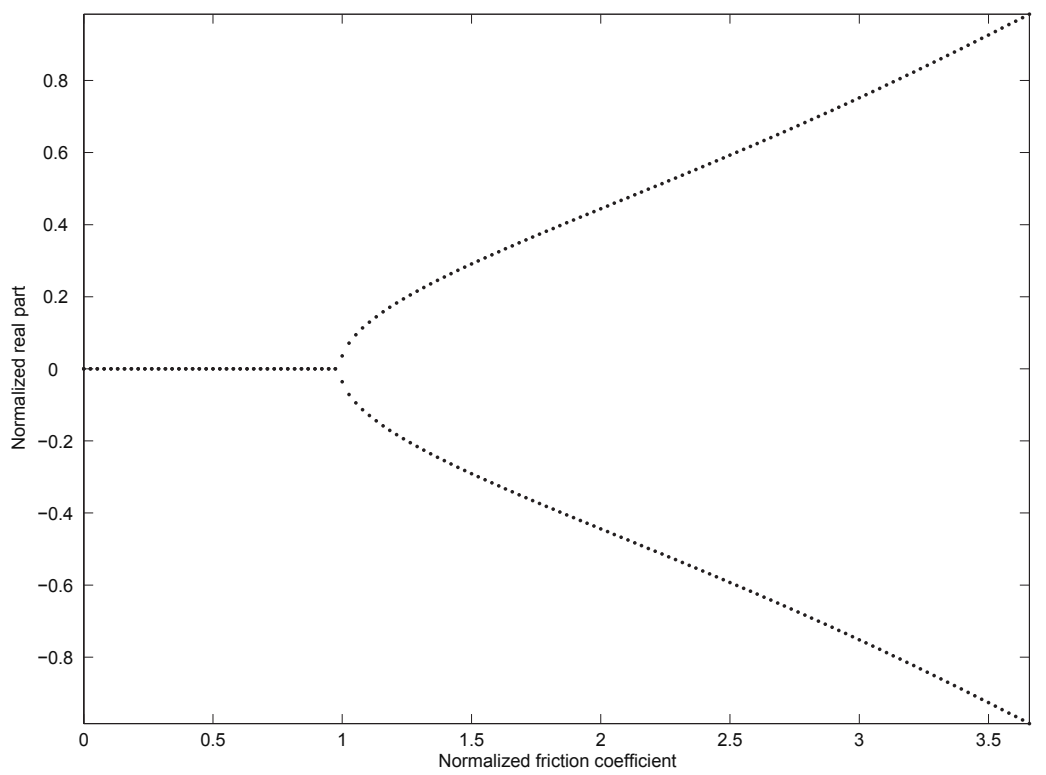

Figure 4. Evolution of the real parts as a function of the friction coefficient 
As shown in Figures 3 and 4, the brake features initially (ie at $\mu=0$ ) two modes apart in frequency and stable since its real parts are zero. Hence, the frequencies tend to get closer as the friction coefficient increases. As soon as the two modes have reached the same frequency, the system behaviour is deeply altered. Indeed, the system has reached the bifurcation point referred to as the coalescence point. Note that the friction coefficient values have been normalized with respect to that point. Then, the frequencies remain equal and the real parts leave progressively the abscissa axis as the friction coefficient increases. One of the two modes features a positive real part whereas the other features the opposite one. As mentioned in the previous section, it means that the first one is stable and the other one is unstable. Note that on Figure 3, dots are for stable modes and crosses for unstable ones.

In an actual brake system, the friction coefficient value can be assessed by measurements. Nevertheless the study of the eigenvalues variability with respect to the friction coefficient leads to the root cause of the phenomena. Indeed it makes it possible to identify the non-friction modes responsible for the mode coupling. The non-friction modes here referred to as $M_{1}$ and $M_{2}$ have respectively a normalized frequency of 0.992 and 1.007. The deformed shapes of those two modes are illustrated in Figures 5 and 6, respectively. $M_{1}$ is a real mode involving most of the brake components. The knuckle mounts vibrate out of phase in the disc axis direction and drive the anchor bracket, which undergoes a complicated twisting mode. The disc features a 3 nodal diameter bending mode and the inner pad slides as a rigid body along the disc surface. The first bending of the caliper is the dominant feature of $M_{2}$. This mode involves also the first bending of the inner pad and compression of the outer pad. Like $M_{1}, M_{2}$ features a 3 nodal diameter disc bending mode. As $M_{1}$ and $M_{2}$ are real modes, they are very useful. Indeed, they are far easier to figure out than the complex modes at stake as soon as the system is unstable. For instance, the complex deformed shape at $\mu=2.5$ is displayed Figure 7 with a phase of 0 degree.
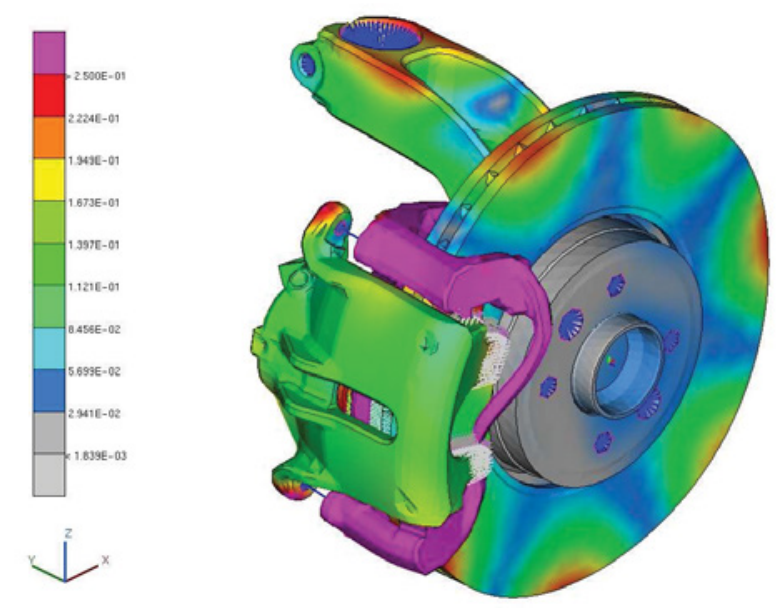

Figure 5. Deformed shape of $M_{1}$ - normalized frequency: 0.992 

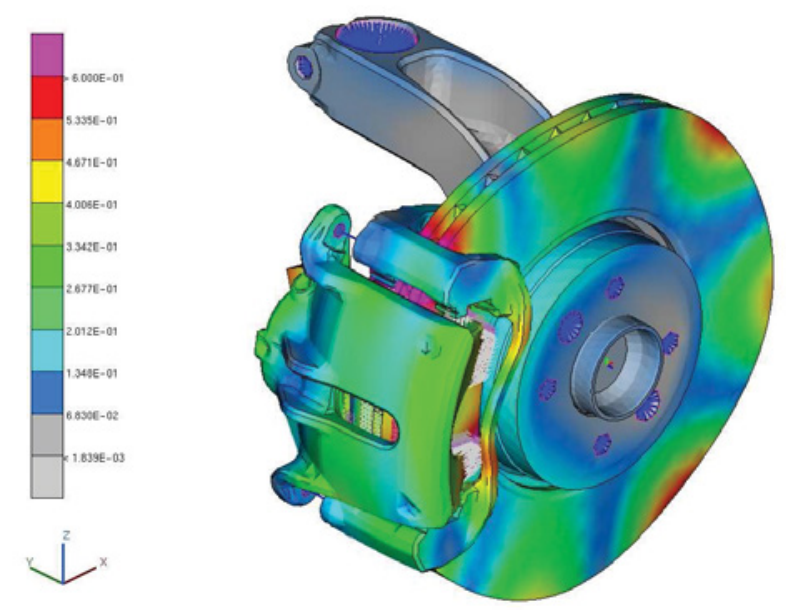

Figure 6. Deformed shape of $M_{2}$ - normalized frequency: 1.007
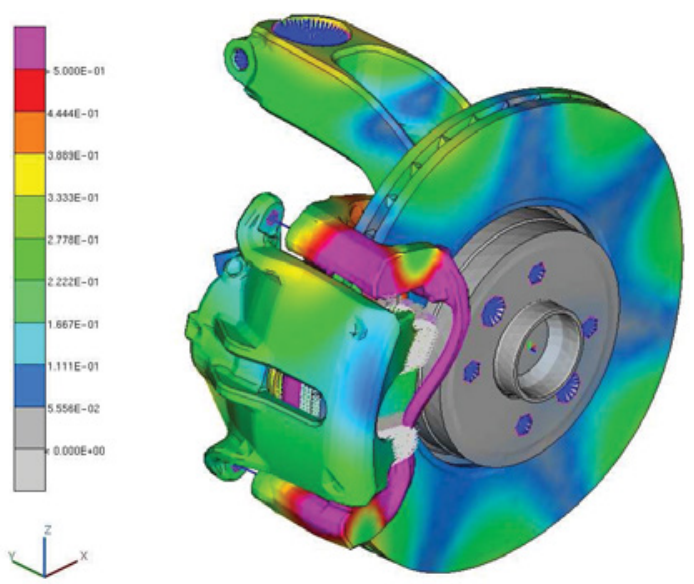

Figure 7. Complex deformed Shape $\mu=2.5, \phi=0^{0}$ - normalized frequency: 1.0

This complex mode shares the same 3 nodal diameter disc bending with $M_{1}$ and $M_{2}$. The inner pad slides along the disc surface and bends like its first free-free bending mode. The outer pad rotates with respect to its center of gravity in the direction of the disc axis. The anchor bracket vibrates in an anti symetric way and the caliper undergoes a mix of bending and twisting mode.

Since the mode is complex, the displacements are not in phase for each DOF. That point can be observed by animating the deformed shape. In order to check the results, the mode that shows the largest real parts (Figure 2) has been compared with the main experimental squealing mode. The correlation turns out to be very good both in terms of frequency and deformed shape. 
All the curves displayed until now described the forward direction behaviour of the brake. To go further, the forward and backward behaviors of the brake have been plotted on the same graph in figure 8 as a function of $\operatorname{sign}(v) \mu$. As mentioned previously, $\operatorname{sign}(v)$ has been defined as positive in the forward direction. Thus, the left part of the figure $(\operatorname{sign}(v) \mu<0)$ represents the backward modes whereas the right part $(\operatorname{sign}(v) \mu>0)$ is for the forward direction.

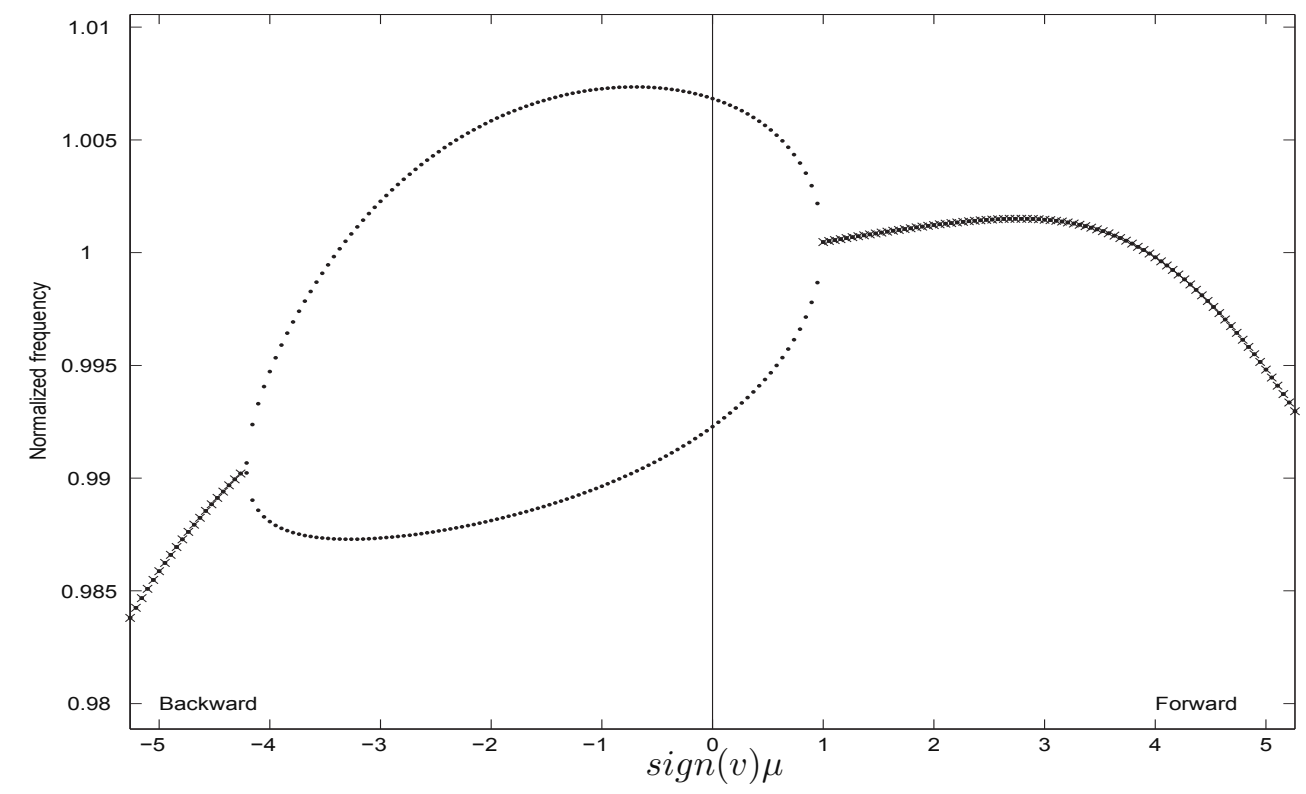

Figure 8. Sensitivity frequency with $\mu$ - forward and backward directions

\section{Sensitivity analysis with respect to the disc Young modulus}

So far, we have studied the behaviour variability of the brake system with respect to the parameter which is the root cause of instabilities: the friction coefficient. Nevertheless, when $\mu$ is set to a non-zero value, the brake stability depends on its modal behaviour. That is to say that it depends on each FE model parameter. Since unstable modes are often driven by a disc contribution, its Young modulus $(E)$ has been chosen as the parameter of variability analysis.

A full factorial design of experiment (DOE), that features 101 values of $\mu$ (50 forward, 50 backward) and 21 of $E$, has been planed. The Young modulus values, which have been normalized, range from 0.0 to 1.0. This range has been chosen symmetric with respect to the nominal value, 0.5 , used in the previous section. The $D O E$ results will be used in the next sections to try to figure out the phenomena at stake and to synthesize the robustness of the brake behaviour. 


\subsection{Behaviour variability}

In order to have a first idea on the system eigenvalues variability with respect to the disc Young modulus, Figure 9 shows, in the vicinity of the squealing mode frequency, all the DOE eigenvalues in the complex plane. The obtained pattern is quite complex as $E$ and $\mu$ are varying simultaneously. However this graph indicates that the variability may be either smooth (in the lower part for the frequency range $[0.97-1.01]$ ) or rough (in the upper part of the graph for the frequency range $[1.01-$ $1.05]$ ). The system seems to shift from a kind of behaviour to another. To go further, the eigenvalues variablities with respect to $\mu$ and $E$ have to be analyzed deeper. Ten plots have been gathered in Figures 10,11, 12, 13 and 14 to explain the relationship between $\mu, E$ and coalescences.

These figures focuse on the evolution of four modes referred to as $M_{1}, M_{2}, M_{3}$ and $M_{4}$ respectively, by increansing frequency. The state $(\mu=0, E=0.5)$ has been chosen as a reference to describe the deformed shapes of those modes, since it depends on both parameters. The deformed shapes of $M_{1}$ and $M_{2}$ had been displayed in the previous section, Figures 5 and 6 . The deformed shapes of $M_{3}$ and $M_{4}$ are shown in Figures 15 and 16.

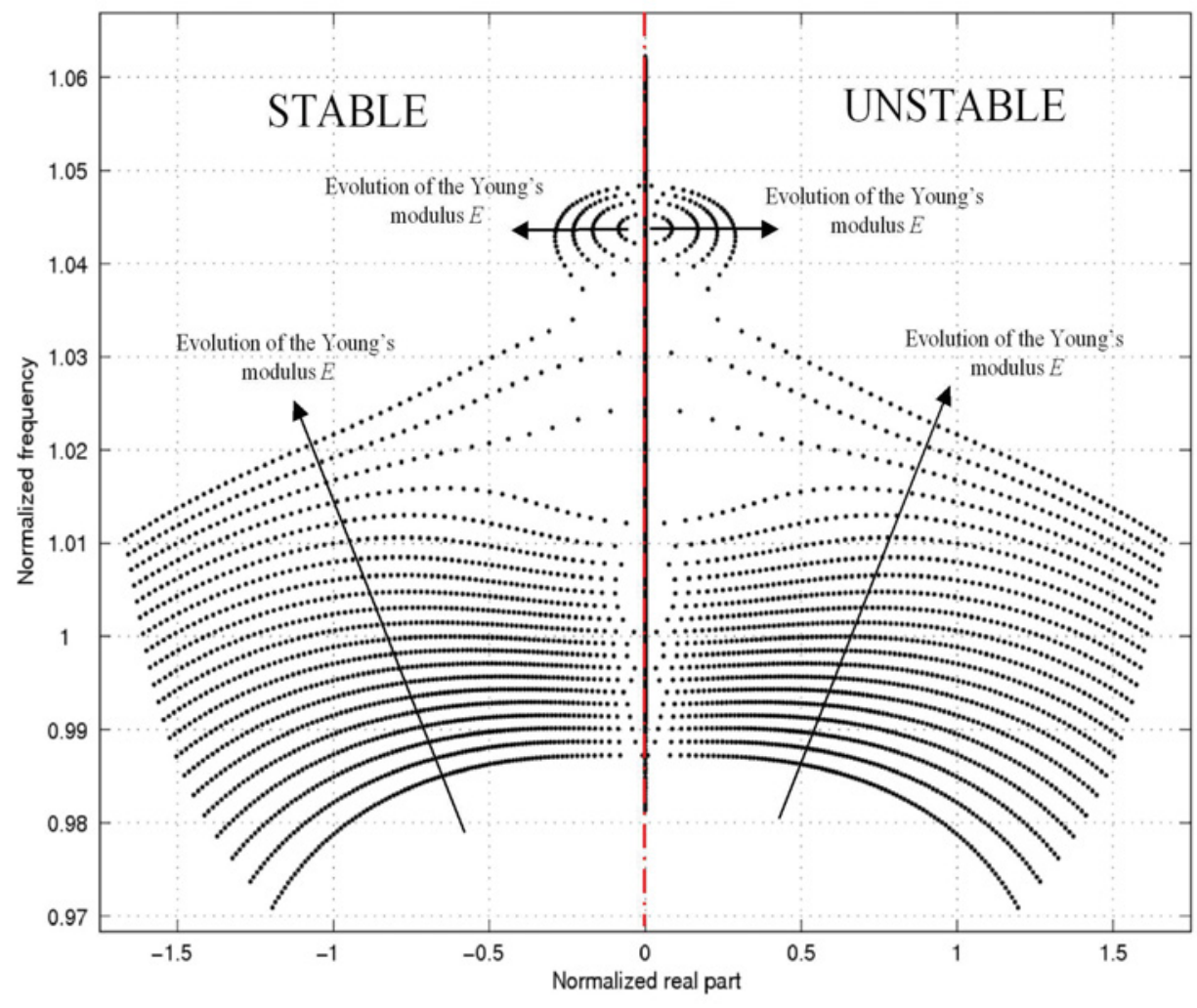

Figure 9. Eigenvalues variability with $\mu$ and $E$ 

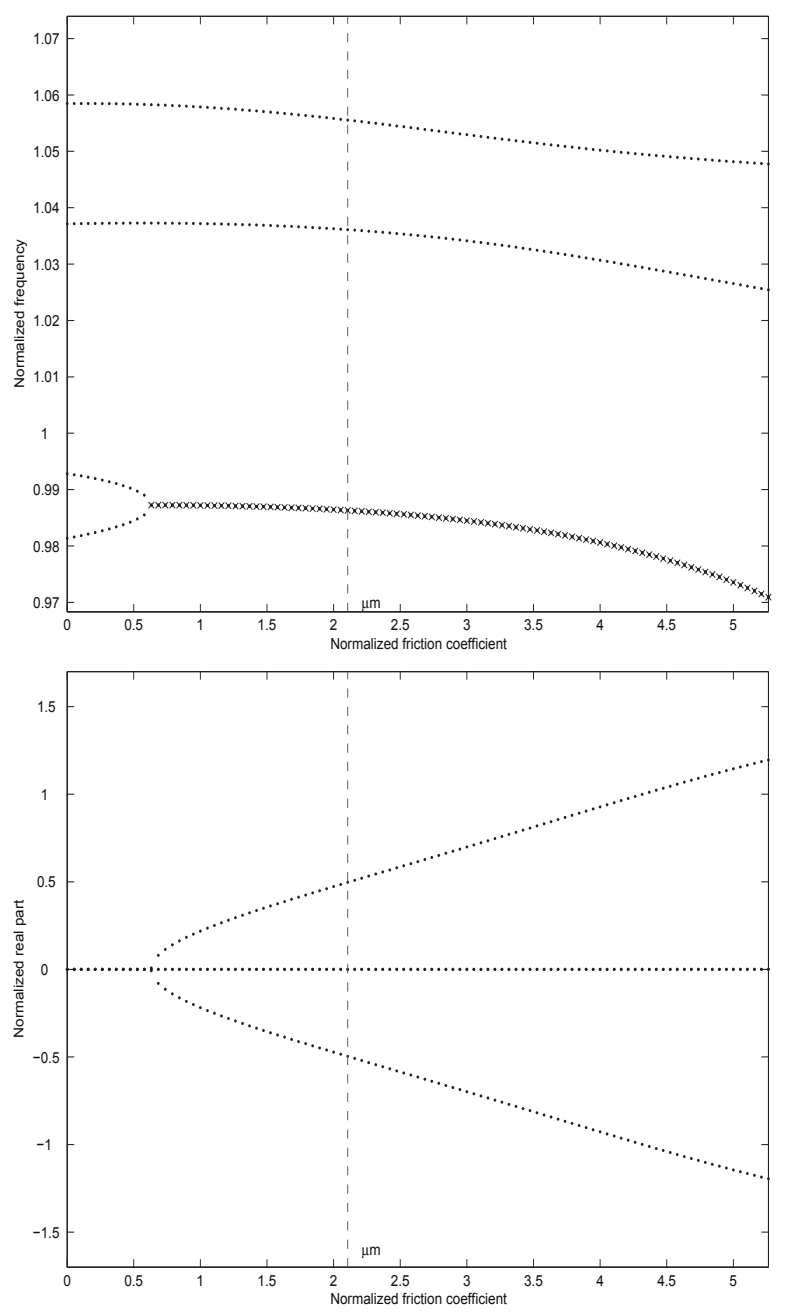

Figure 10. Variability $\lambda=f(\mu, E), E a=0.00$

$M_{3}$ features a normalized frequency of 1.039 and its deformed shape is the following. The knuckle mounts vibrate in phase in the disc axis direction and drive the anchor bracket in a symetric mode. The caliper undergoes a first twisting mode. The inner pad slides as a rigid body along the disc surface and the outer pad rotates with respect to its center of gravity in the direction of the disc axis. The disc vibrates, with a low magnitude, like a mix of an umbrella mode and a 2 nodal diameter mode. The deformed shape of $M_{4}$, which normalized frequency is 1.060 , looks like the $M_{3}$ one. Nevertheless, $M_{4}$ is out of phase with respect to $M_{3}$ and the magnitude of the caliper displacements is larger.

The eight first graphs (Figures 10,11, 12 and 13) show the frequency and real part variability versus the friction coefficient respectively for four disc Young modulus values referred to as $E a=0.00, E b=0.75, E c=0.85$ and $E d=1.00$. For the first value, $E a=0.00$, the two lower frequency modes get coupled at $\mu=0.6$. For $E b=0.75$ this two modes become also unstable, but the coalescence point is shifted toward the higher values of $\mu$. Another point to mention on this graph is the trend of 

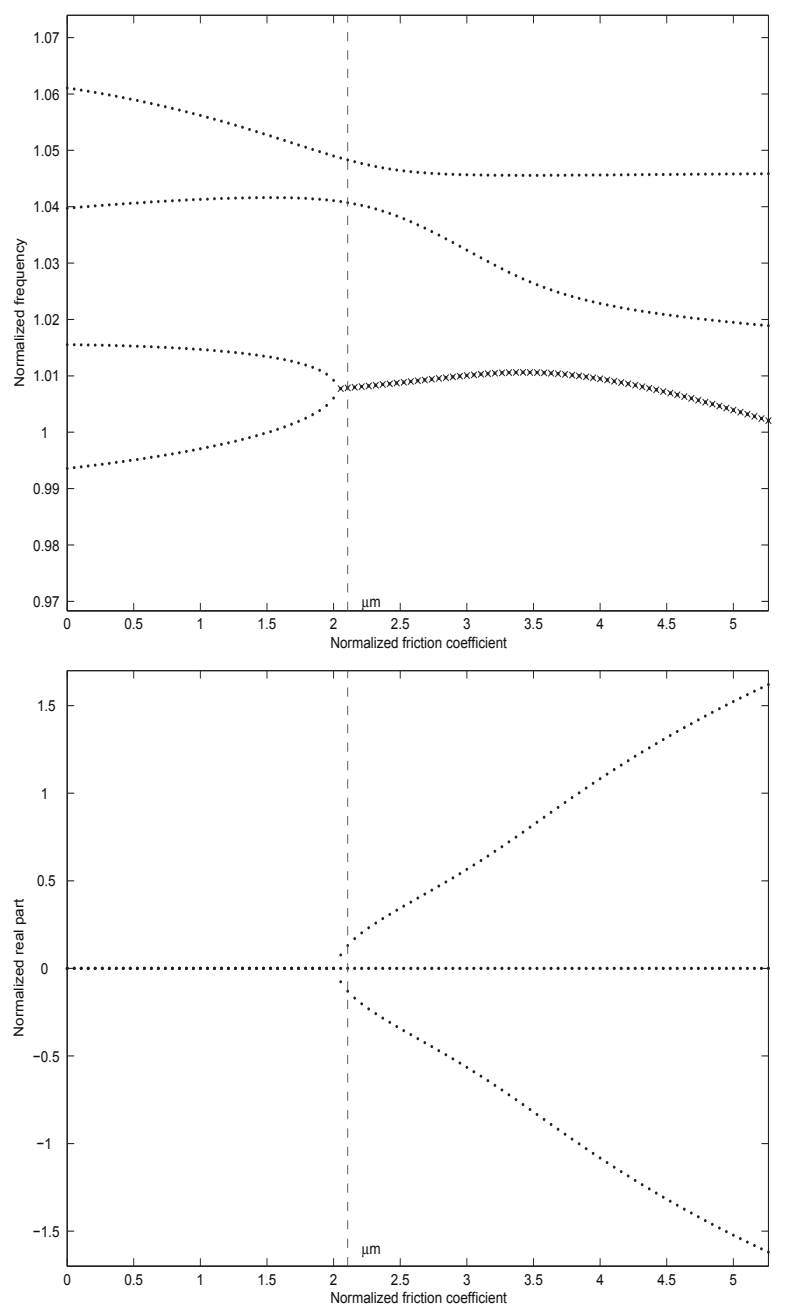

Figure 11. Variability $\lambda=f(\mu, E), E b=0.75$

the two higher frequency modes to get closer in the vicinity of $\mu=2.1$. This trend is confirmed on the $E c=0.85$ graph since these two modes are unstable on the friction coefficient range $[1.9-2.4]$. On this range, the real part magnitudes increases and then decreases versus the friction coefficient. This phenomenon is noticeable as circle shaped patterns on Figure 9. Meanwhile, the two lower frequency modes coalescence point is once again shifted toward the higher values of $\mu$. After this coalescence point, the frequencies of the two coupled modes seem to be influenced by the nearest upper mode as its deflection becomes sharper. This leads to the $E d=1.00$ situation. The two higher frequency modes get coupled at $\mu=1.4$. Then a third mode makes its paths diverge at $\mu=2.6$. One of the two released modes get immediately coupled with the third mode. That is the reason why the curves intersect with a vertical tangent. Then the forth mode cross the two coupled ones at $\mu=4.5$. As the tangent is not vertical, it can be inferred that this intersection does not alter the coupling pattern. 

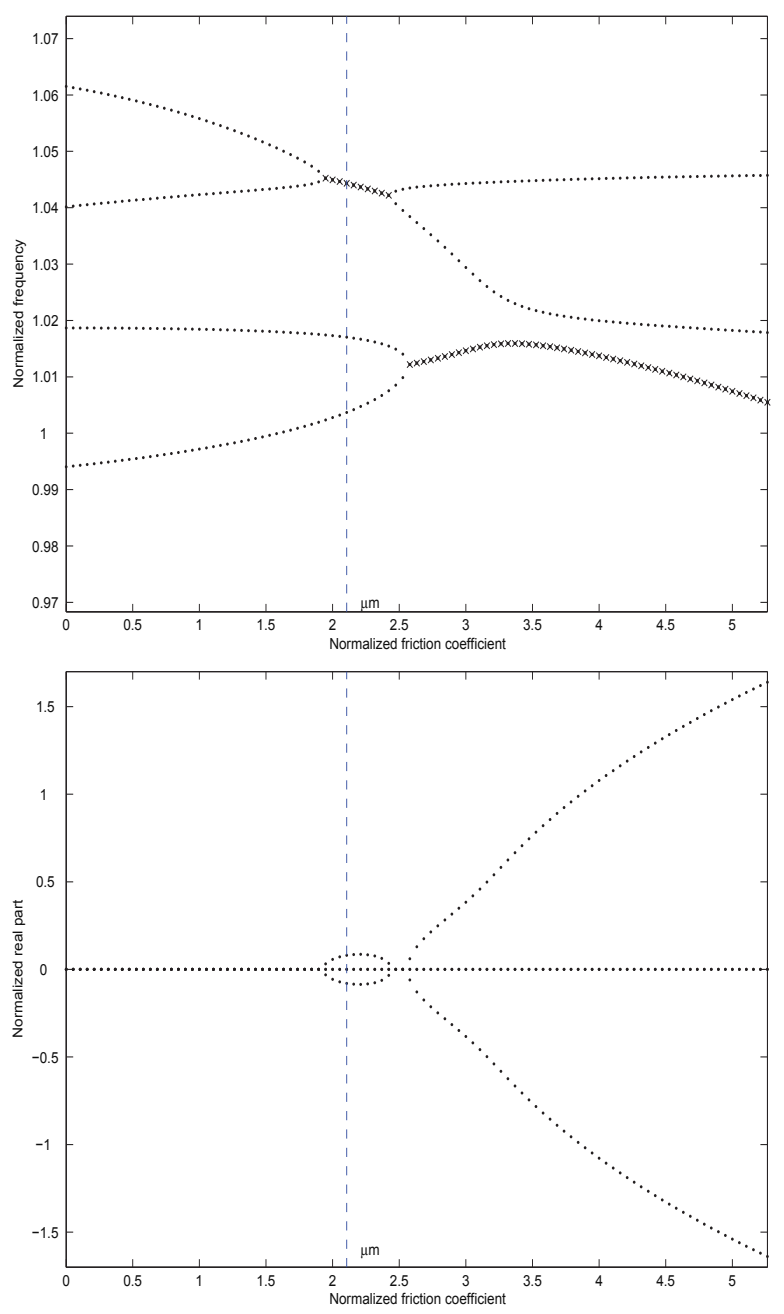

Figure 12. Variability $\lambda=f(\mu, E), E c=0.85$

The eigenvalues variability as a function of $E$ is now investigated. Figure 14 shows the frequencies and real parts sensitivity with respect to $E$ for $\mu=2.1$. This value of the friction coefficient will be referred to as $\mu \mathrm{m}$ in the following. In order to link the sensitivity graphs with respect to $E$ and to $\mu$, vertical dashed lines have been superimposed. One line marks $\mu m=2.1$ on each variability with friction graph and four lines mark respectively $E a=0.00, E b=0.75, E c=0.85, E d=1.00$ on the $\mu m=2.1$ variability with E graphs. The noteworthy point is that sensitivities with $\mu$ and with $E$ features the same topology. Indeed, data may be interpreted in terms of coalescence and of mode coupling. Figure 14 shows that, for $\mu m=2.1$ the two higher frequency modes are stable until they couple for $E=0.85$. The two lower frequency modes are coupled on the range $[0.00-0.75]$ of $E$ and separate further. Nevertheless, the key difference between $\mu$ and $E$ as variability parameters is that increasing $\mu$ generally strengthens the mode coupling, whereas such a trend does not exist for $E$. 

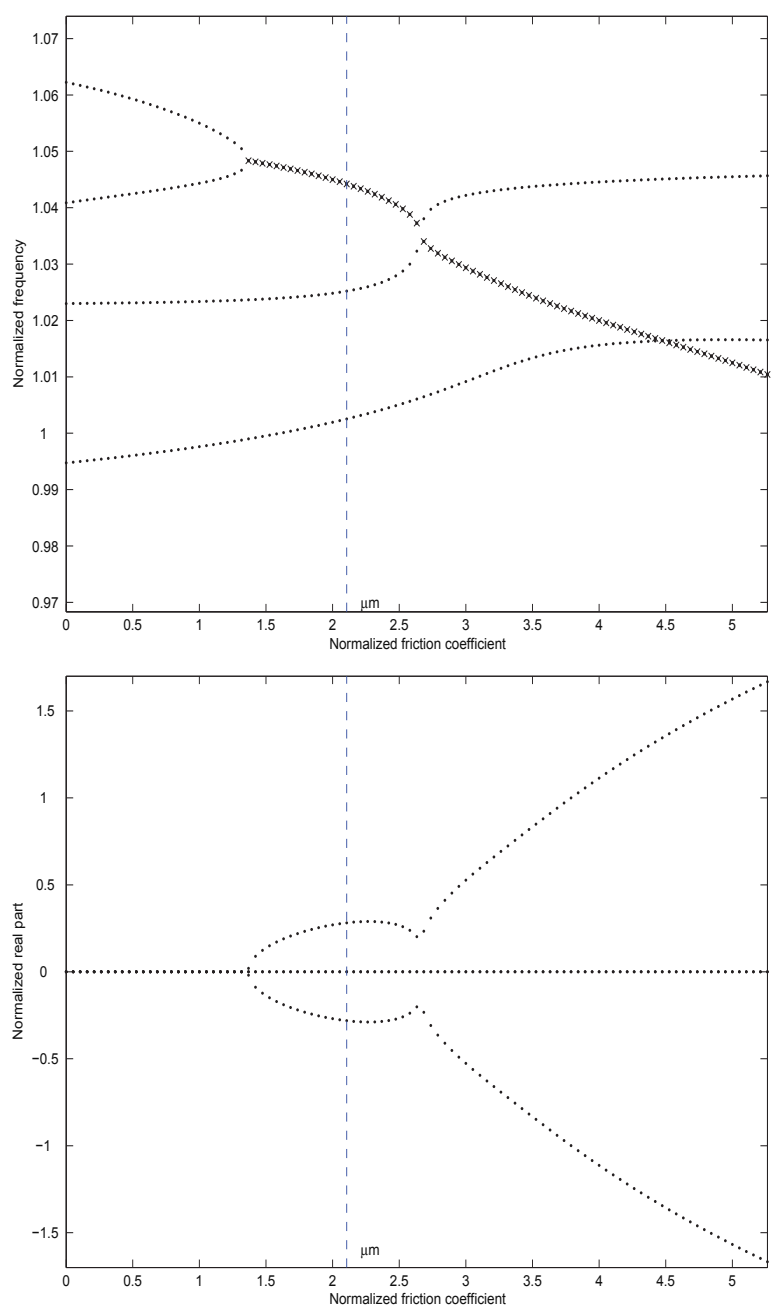

Figure 13. Variability $\lambda=f(\mu, E), E d=1.00$

\subsection{Stability areas}

The previous section shows that brake squeal is a very sensitive multi parametric phenomenon. Nevertheless, according to the driver point of view, no matter how complex it may be the brake must be quiet in each operational condition. This tackles the concept of robustness. In order to assess the brake robustness in terms of squealing behaviour, a new kind of plot has been developed to synthesize the large amount of DOE data available. The number of unstable modes has been counted and displayed as a colormap in the $\mu-E$ plane. Figures 17 and 18 show six graphs respectively for the frequency ranges referred to as A, B, C, D, E and F. The corresponding normalized frequencies are gathered in Table 1.

Note that both forward and backward behaviours are displayed. The lightest colour marks the stable area whereas the two darker ones represents increasingly unstable conditions: respectively one and two instabilities. At least for the lower frequency ranges, the areas are quite smooth and well defined. That tends to prove that the 

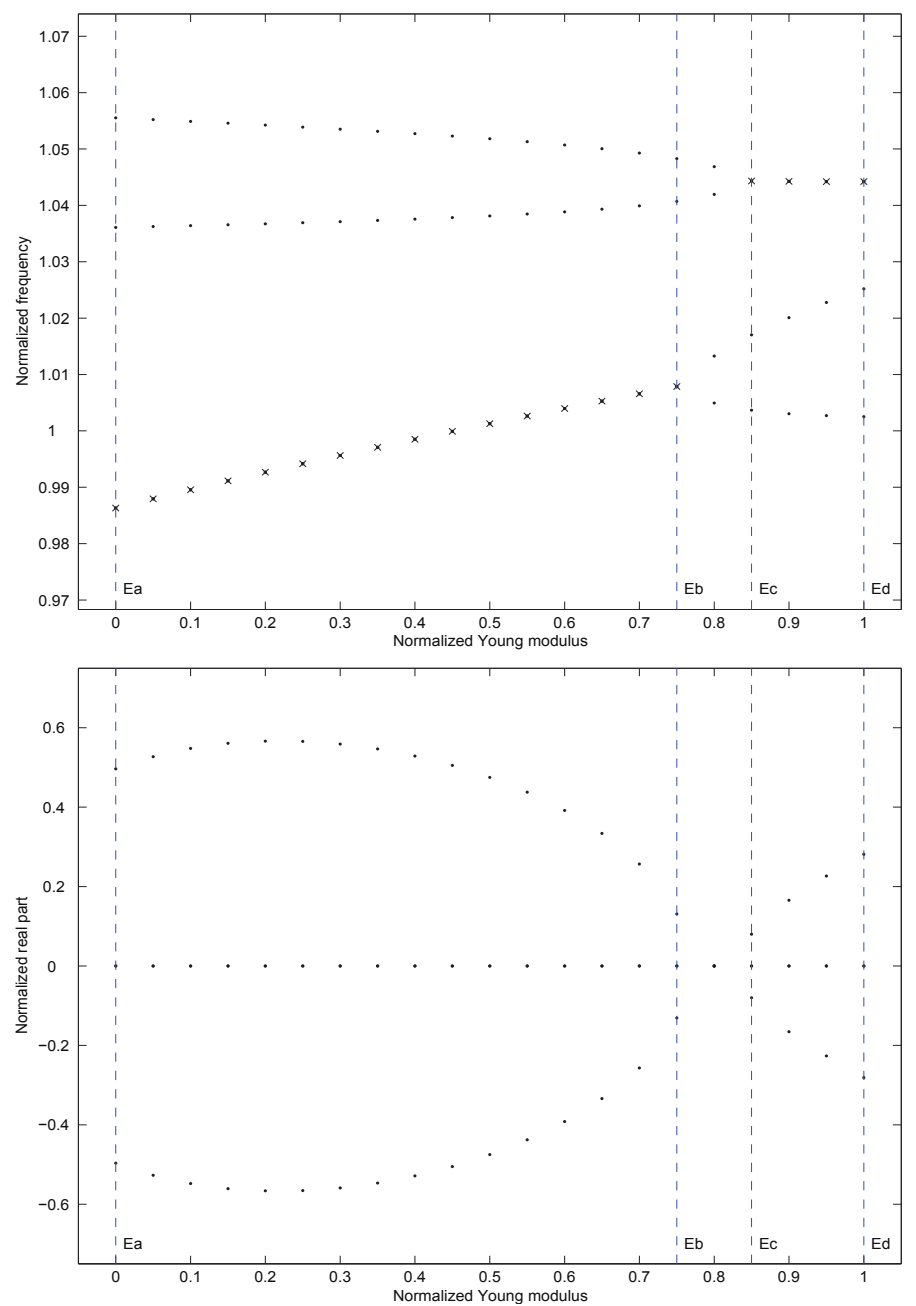

Figure 14. Variability $\lambda=f(\mu, E), \mu m=2.1$

Table 1. Normalized frequency ranges

\begin{tabular}{|c|c|}
\hline Name & Normalized frequency range \\
\hline A & $0.00-0.35$ \\
B & $0.35-0.70$ \\
C & $0.70-1.05$ \\
D & $1.05-1.40$ \\
E & $1.40-1.75$ \\
F & $1.75-2.10$ \\
\hline
\end{tabular}



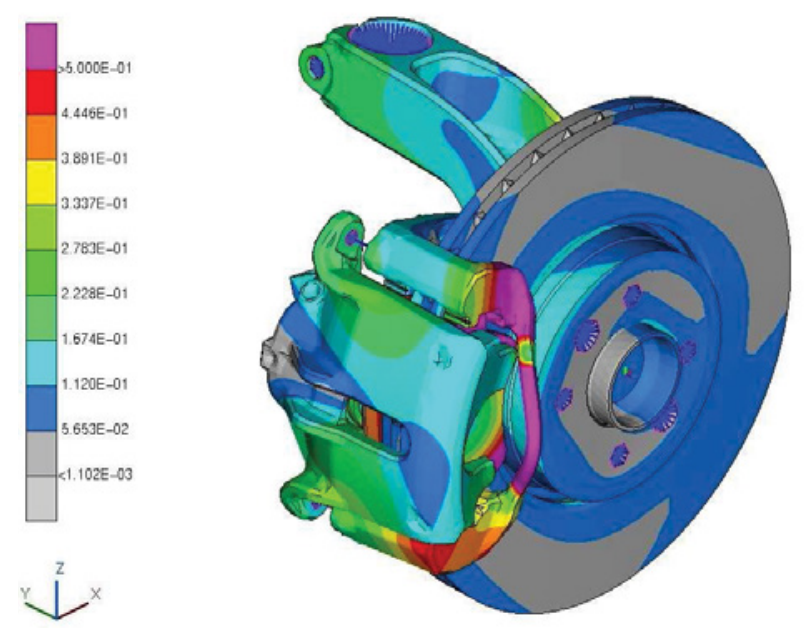

Figure 15. Deformed shape of $M_{3}$ - normalized frequency: 1.039
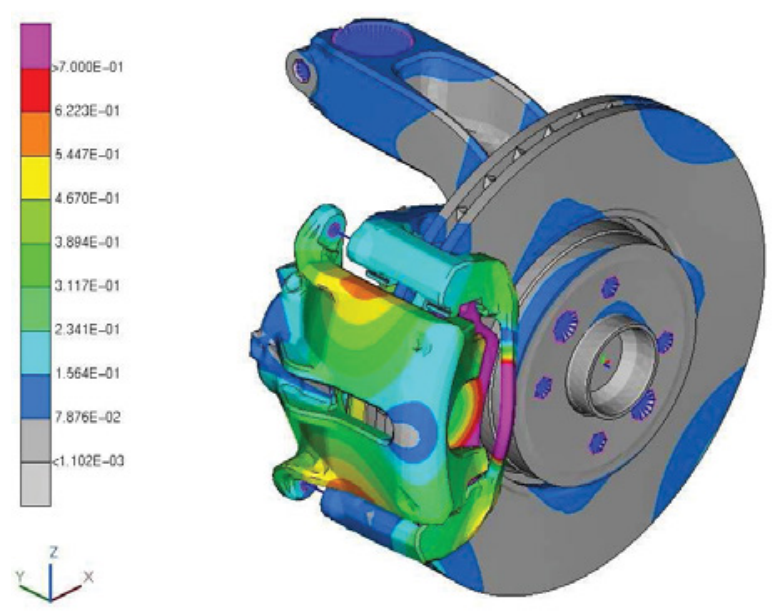

Figure 16. Deformed shape of $M_{4}$ - normalized frequency: 1.060

sampling of Young modulus is sufficient. In the frequency range A $(0-0.35)$, the stable-unstable border is almost a straight line. Whatever the Young modulus value, the brake squeals for the same friction coefficient value. In the frequency range $B$ $(0.35-0.70)$, the situation is quite different. The brake is stable forward and unstable backward. The backward unstable area reaches a maximum around $E=0.15$. In this situation, the brake stability might be improved by choosing the $E$ value which maximize the stable area: $E=0.00$. In that case, the brake begins to squeal backwards at $\mu=2.5$. Nevertheless, this state is not robust. Indeed, since the border slopes are large, a small variation in $E$ will worsen drastically the brake behaviour. Here a 0.15 shift of the Young modulus value makes the critical friction jump from $\mu=2.5$ to $\mu=0.1$. If the solution $E=0.8$ had been chosen the brake would have been less 


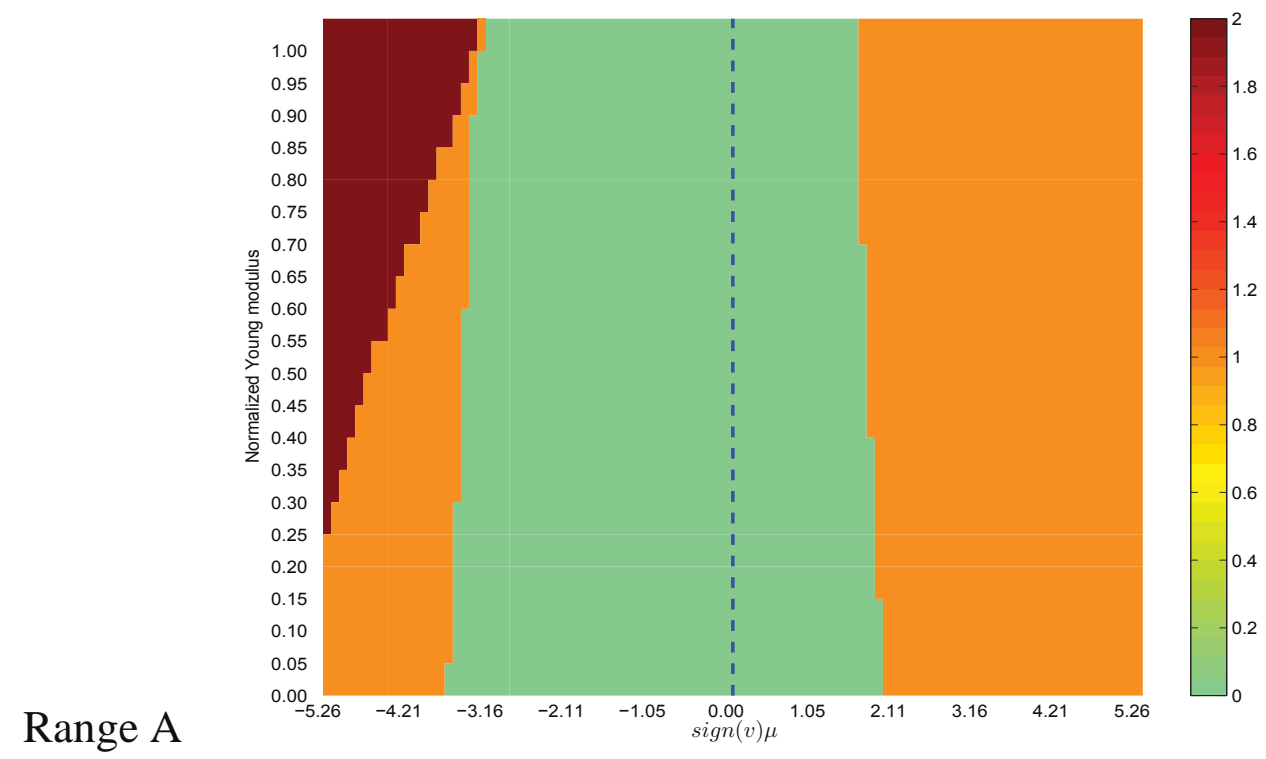

Range B
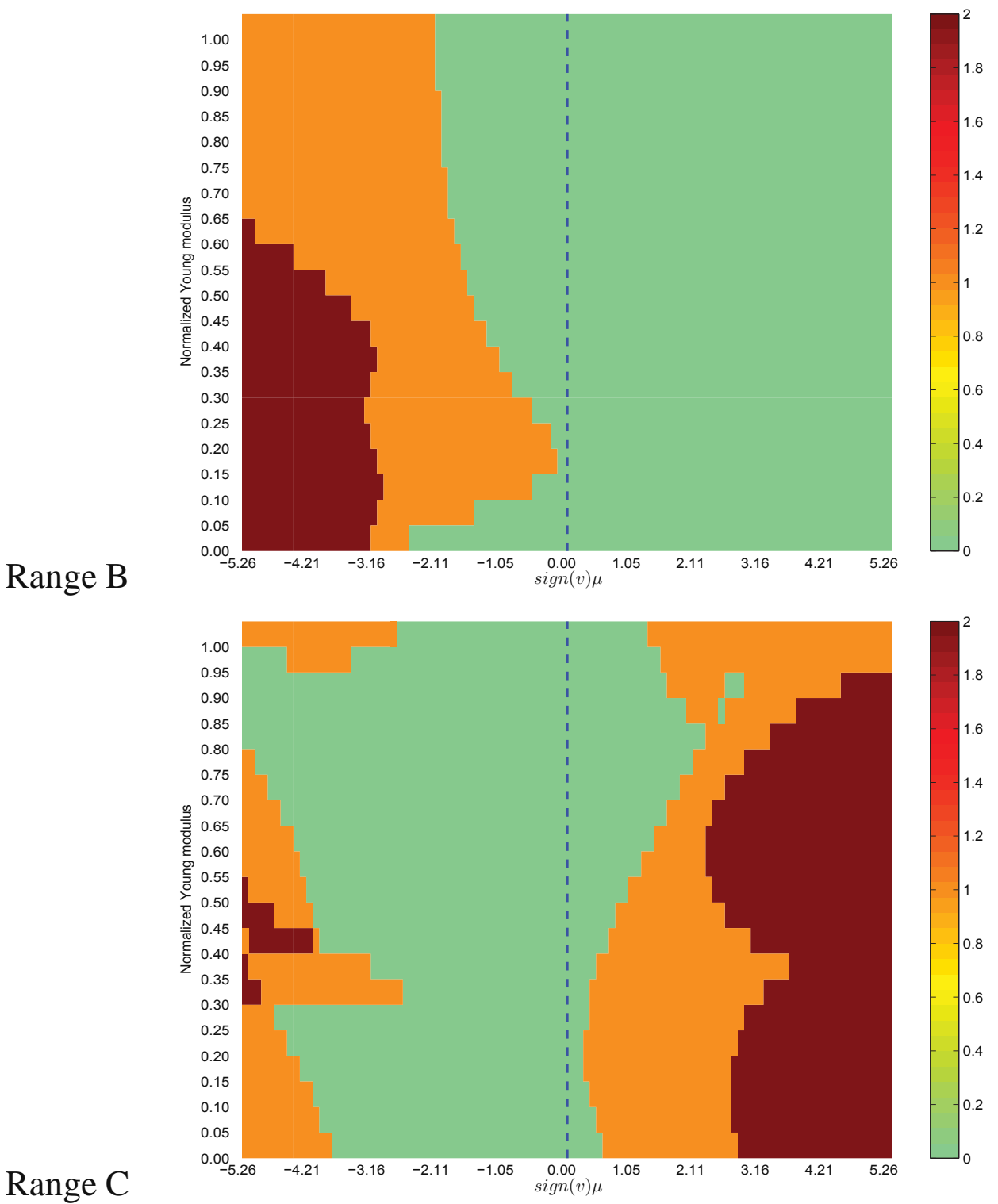

Figure 17. Stability charts versus frequency range 


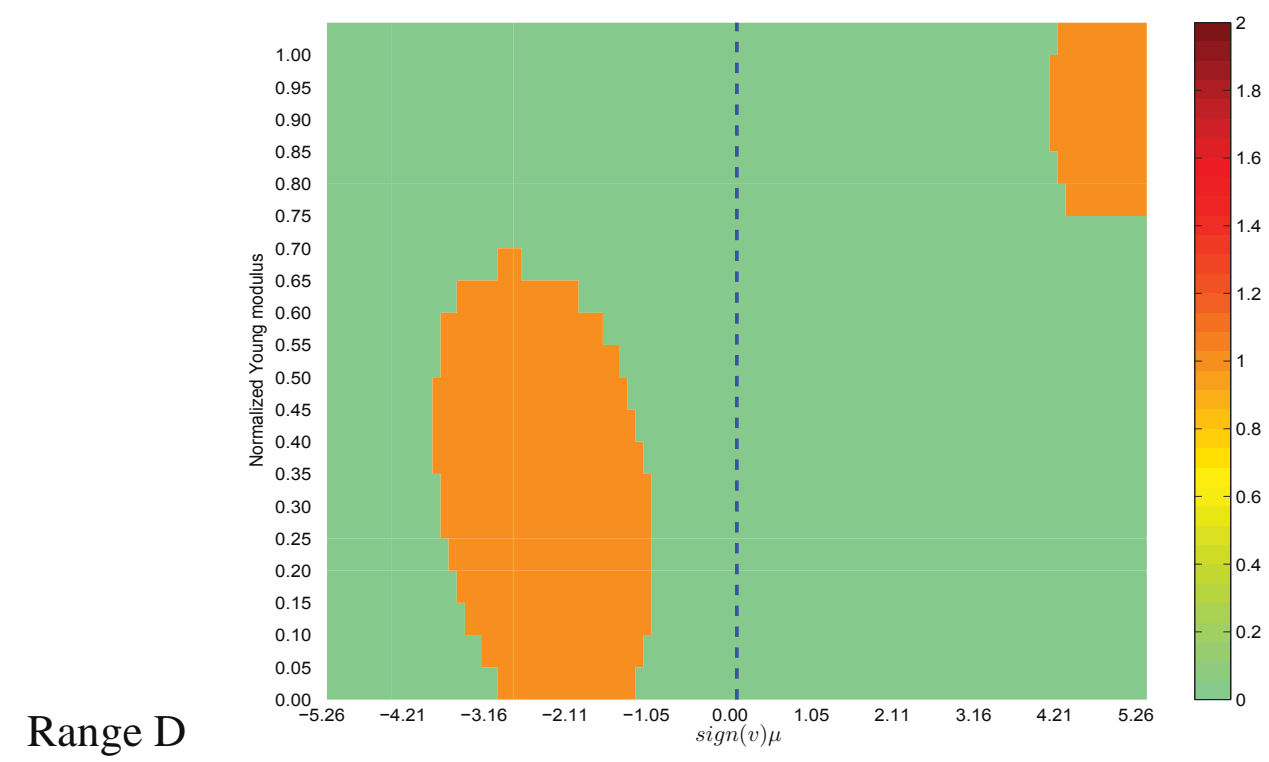

Range E
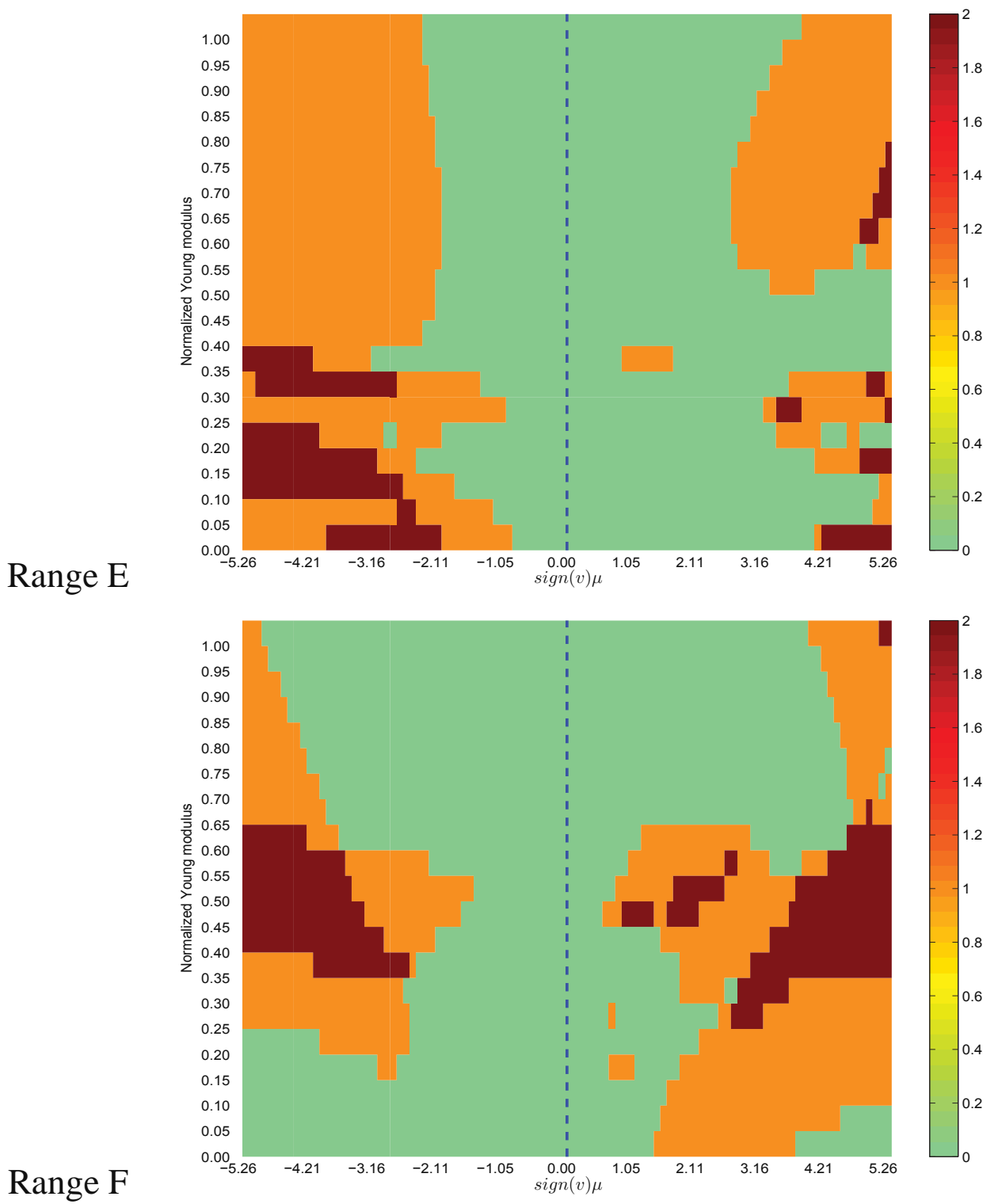

Figure 18. Stability charts versus frequency range 
performant but more robust. In the frequency range $C(0.70-1.05)$, the pattern is a bit more complicated. Forward, the brake is the most unstable for $E=0.2$ and the most stable for $E=0.8$. In the vicinity of that local maximum, a decoupling phenomenon can be observed as a stable area surrounded on the unstable side. The second border, which marks the second coalescence appearance, features two local maxima and one local minimum respectively $E=0.10, E=0.60$ and $E=0.35$. Backward, the border slop decreases from $E=0.00$ to $E=0.25$. The critical friction coefficient value suddenly jumps from $\mu=4.5$ to $\mu=2.0$. Hence, the border slope decreases again until $E$ reaches 0.8 . On the range D $(1.05-1.40)$, the stability pattern is mainly based on a coupling - decoupling backward phenomenon. The noteworthy point on ranges $\mathrm{E}$ and $\mathrm{F}(1.40-1.75$ and $1.75-2.10)$ is that the stability patterns features two different trends. On the one hand, stability borders are mainly smooth looking. But on the other hand, in some areas, parameters seem to be too under sampled to figure out the actual stability behaviour. The last chart, Figure 19, aims at summing up the overall stability of the brake, from 0 to 2.10 in terms of normalized frequencies. It presents a bottleneck in the vicinity of $E=0.15$ and shows that increasing the disc Young modulus tends to widen the stable area. Nevertheless, it must be kept in mind that instabilities displayed on that graph may be induced by very different phenomena. For instance a low frequency instability and a high frequency squeal have here the same weight.

\section{Conclusion}

In this paper, a parametric study of brake squeal has been carried out on an actual front brake. The method consists in a complex eigenvalue analysis on the brake FE model. A technique of modal basis projection has been used to assess the dependency as a function of the friction coefficient. With this technique, a full factorial design of experiment has been launched to study the squeal sensitivity with respect to two parameters: the friction coefficient and the disc Young modulus. The reasons of this choice are that squeal is a friction induced instability and that unstable modes often involve a disc bending mode component. The large amount of data computed has been analysed with respect to both parameters. The noteworthy point is that the eigenvalues sensitivity curves with respect to the first and to the second parameter have the same topology. Indeed, they may be both analysed in terms of mode coupling also referred to as coalescence. The coupling patterns turn out to be complicated and highly sensitive. This key point, which had been highlighted by experiments, has been here forecasted by computations. The brake stability has been synthesized on stability charts based on the DOE data. This kind of chart, which point out the stable and unstable areas, is very useful to assess the brake robustness in terms of squeal. Therefore, the optimal parameters values can be chosen. This optimal configuration might

not be the most performant one, but the best one in terms of performance - robustness compromise. 


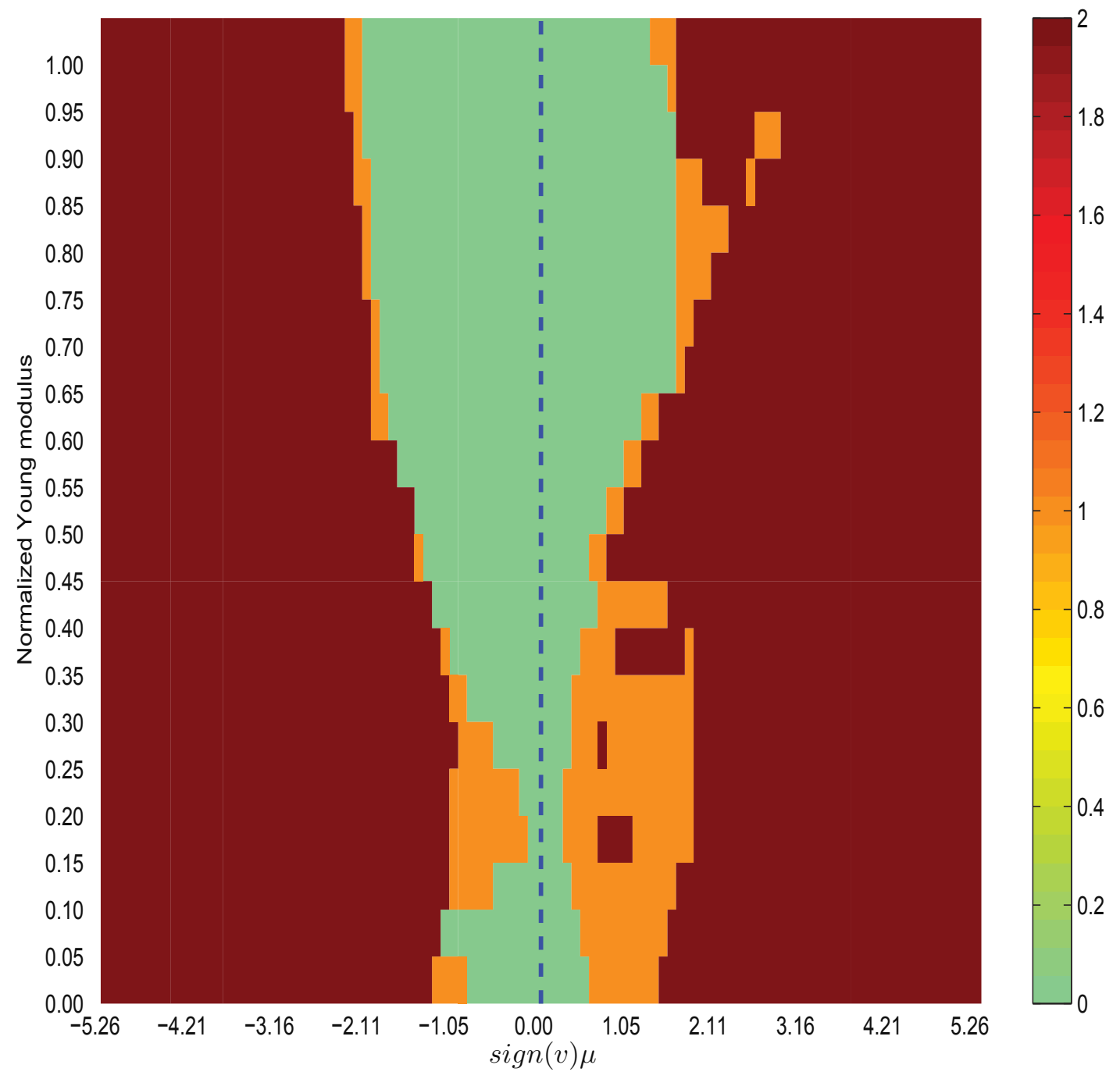

Figure 19. Stability chart on the overall frequency range

\section{References}

Antoniou S., Cameron A., Gentle C., “ The Friction-Speed Relation from Stick-Slip Data”, Wear, vol. 36, p. 235-254, 1976.

Baillet L., D’Errico S., Laulagnet B., “ Understanding the occurrence of squealing noise using the temporal finite element method”, Journal of Sound and Vibration, vol. 292, n ${ }^{\circ} 3-5$, p. 443-460, 2006.

Baillet L., D’errico S., Linck V., Laulagnet B., Berthier Y., “ Finite element simulation of dynamic instabilities in frictional sliding contact”, Journal of Tribology, vol. 127, n 3, p. 652-657, 2005.

Barnejee A., “ Influence of Kinetic Friction on the Critical Velocity of Stick-Slip Motion”, Wear, vol. 12, p. 107-116, 1968.

Blaschke P., Tan M., Wang A., “ On the Analysis of Brake Squeal Propensity Using Finite Element Method”, SAE paper 2000-01-2765, 2000. 
Chung C., Donley M., “ Mode Coupling Phenomenon of Brake Squeal Dynamics”, SAE paper 2003-01-1624, 2003a.

Chung C., Steed W., Dong J., Kim B., Ryu G., “ Virtual Design of Brake Squeal”, SAE paper 2003-01-1625, 2003b.

Chung C., Steed W., Kobayashi K., Nakata H., “ A new Analysis Method For Brake Squeal Part I : Theory For Modal Domain Formulation And Stability Analysis”, SAE paper 2001-011600, 2001.

Crolla D., Lang A., “ Brake Noise and Vibration - State of Art”, Tribologie-Vehicle Tribology, vol. 18, p. 165-174, 1991.

Dihua G., Dongying J., “ A study on disc brake squeal using finite element methods”, SAE paper 980597, 1998.

Earles S., Chambers P., “ Disque Brake Squeal Noise Generation: Predicting its Dependency on System Parameters Including Damping”, Int. J. of Vehicle design, vol. 8, p. 538-552, 1987.

Earles S., Lee C., “ Instabilities Arising from the Frictional Interaction of a Pin-Disc System Resulting in Noise Generation”, Trans. ASME J. Engng Ind., vol. 1, p. 81-86, 1976.

Gao C., Kuhlmann-Wilsdorf D., Makel D., “ The Dynamic Analysis of Stick-Slip Motion”, Wear, vol. 173, p. 1-12, 1994.

Hulten J., “ Brake Squeal - A Self-Exciting Mechanism with Constant Friction”, Society of Automotive Engineers, paper 932965, 1993.

Ibrahim R., “ Friction-Induced Vibration, Chatter, Squeal, and Chaos. Part 1 : Mechanics of Contact and Friction”, ASME Design Engineering Technical Conferences, vol. 7, p. 209226, 1994a.

Ibrahim R., “ Friction-Induced Vibration, Chatter, Squeal, and Chaos. Part 2 : Dynamics and Modeling”, ASME Design Engineering Technical Conferences, vol. 7, p. 209-2269, 1994b.

Jarvis R., Mills B., “ Vibrations Induced by Dry Friction”, Proc. Instn. Mech. Engrs, paper 32,p. 847-866, 1993.

Kinkaid N., O’Reilly O., Papadopoulos P., “ Automotive disc brake squeal”, Journal of Sound and Vibration, vol. 267, p. 105-166, 2003.

Kobayashi M., “ Sound and Vibration in Brakes”, Japanese Journal of Tribology, vol. 35, p. 561-567, 1990.

Lorang X., Foy-Margiocchi F., Nguyen Q., Gautier P., “ TGV disc brake squeal”, Journal of Sound and Vibration, vol. 293, p. 735-746, 2006.

Matsui H., Murakami H., Nakanishi H., Tsuda Y., “ Analysis of disc brake squeal”, SAE paper 920553, 1992.

Millner N., “ An Analysis of Disc Brake Squeal”, SAE paper 780332, 1978.

Mills H., “ Brake Squeal”, Institution of Automobile Engineers, Research Report 9000b and Research Report 9162B, 1938.

Moirot F., Nehme A., NGuyen Q., “ Numerical Simulation to Detect Low-Frequency Squeal Propensity”, SAE paper 2000-01-2767, 2000a.

Moirot F., Nguyen Q., Oueslati A., “ An example of stick-slip and stick-slip-separation waves”, European Journal of Mechanics-A/Solids, vol. 22, n 1, p. 107-118, 2003.

Moirot F., Nguyen Q., “ An example of stick-slip waves”, Comptes Rendus de l'Académie des Sciences - Series IIB - Mechanics, vol. 328, n 9, p. 663-669, 2000 b. 
Nakata H., Kobayashi K., Kajita M., Chung C., “ A new analysis approach for motorcycle brake squeal noise and its adaptation”, SAE paper 2001-01-1850, 2001.

North M., “ A Mechanism of Disk Brake Squeal”, 14th FISITA Congress, 1972.

Oden J., Martins J., “ Models and Computational Methods for Dynamic Friction Phenomena”, Computer Methods in Applied mechanics and Engineering, vol. 52, p. 527-634, 1985.

Oueslati A., Nguyen Q., Baillet L., “ Stick-slip-separation waves in unilateral and friction contact”, Comptes Rendus Mécanique, vol. 331, n 1, p. 133-140, 2003.

Ouyang H., Mottershead J., Cartmell M., Brookfield D., “ Friction-induced vibration of an elastic slider on a vibrating disc”, Journal of Mechanical Sciences, vol. 41, n 3, p. 325336, 1999.

Ouyang H., Mottershead J., Cartmell M., Friswell M., “ Friction induced parametric resonances in discs : effect of a negative friction velocity relationship”, Journal of Sound and Vibration, vol. 209, n² 2, p. 251-264, 1998.

Ouyang H., Mottershead J., “ Unstable travelling waves in the friction induced vibration of discs”, Journal of Sound and Vibration, vol. 248, n 4, p. 768-779, 2001.

Park C., Han M., Cho S., Choi H., Jeong J., Lee J., “ A Study on the Reduction of Disc Brake Squeal Using Complex Eigenvalue Analysis”, SAE paper 2001-01-3141, 2001.

Rabinowicz E., Friction and Wear of Materials, Wiley \& Sons, 1965.

Sinclair D., Manville N., “ Frictional Vibrations”, Journal of Applied Mechanicsp. 207-213, 1955.

Sinou J., Thouverez F., Jézéquel L., “ Analysis of Friction and Instability by the Center Manifold Theory for a Non-Linear Sprag-Slip Model”, Journal of Sound and Vibration, vol. 265, $n^{\circ}$ 3, p. 527-559, 2003.

Sinou J., Thouverez F., Jézéquel L., “ Methods to Reduce Non-Linear Mechanical Systems for Instability Computation”, Archives of Computational Methods in Engineering: State of the Art Reviews, vol. 11, n³, p. 257-344, 2004.

Spurr R., “ A Theory of Brake Squeal”, Proc. Auto. Div. Instn. Mech. Engrs, vol. 1, p. 33-40, 1961.

Tolstoi D., “ Significance of the Normal Degree of Freedom and Natural Normal Vibrations in Contact Fiction”, Wear, vol. 10, p. 199-213, 1967. 